This item was submitted to Loughborough's Research Repository by the author.

Items in Figshare are protected by copyright, with all rights reserved, unless otherwise indicated.

\title{
Total synthesis of the tetrasubstituted furan fatty acid metabolite CeDFP via
} Au-catalyzed intermolecular alkyne hydroarylation

\section{PLEASE CITE THE PUBLISHED VERSION}

https://doi.org/10.1021/acs.orglett.9b01786

\section{PUBLISHER}

(c) American Chemical Society

\section{VERSION}

AM (Accepted Manuscript)

\section{PUBLISHER STATEMENT}

This document is the Accepted Manuscript version of a Published Work that appeared in final form in Organic Letters, copyright $\odot$ American Chemical Society after peer review and technical editing by the publisher. To access the final edited and published work see https://pubs.acs.org/doi/10.1021/acs.orglett.9b01786.

\section{LICENCE}

CC BY-NC-ND 4.0

\section{REPOSITORY RECORD}

Wang, Yamin, Gareth Pritchard, and Marc Kimber. 2019. "Total Synthesis of the Tetrasubstituted Furan Fatty Acid Metabolite Cedfp via Au-catalyzed Intermolecular Alkyne Hydroarylation”. Loughborough University. https://hdl.handle.net/2134/38181. 


\title{
Total synthesis of the tetra-substituted furan fatty acid metabolite CeDFP via Au-catalyzed intermolecular alkyne hydroarylation
}

\author{
Yamin Wang, Gareth J. Pritchard* and Marc C. Kimber* \\ Department of Chemistry, School of Science, Loughborough University, LE11 3TU, UK.
}

Supporting Information Placeholder
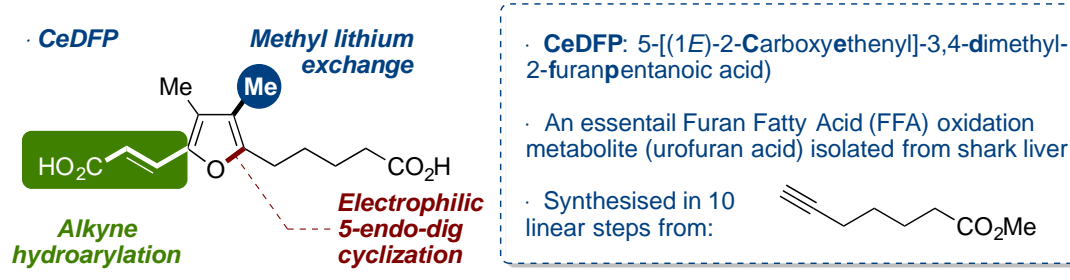

ABSTRACT: The first total synthesis of the tetra-substituted furan fatty acid (FFA) metabolite 5-[(1E)-2-carboxyethenyl]-3,4dimethyl-2-furanpentanoic acid (CeDFP), is reported. CeDFP is a FFA metabolite isolated from shark livers and is related to the known FFA metabolites CMPF and CMPentylF. Key elements of the synthetic route to CeDFP include an iodine promoted 5-endodig cyclization of an 1,2-akyne diol, a methyllithium mediated insertion of the $\mathrm{C}_{3}$-methyl group, and an Au(I)-catalyzed intermolecular hydroarylation to introduce the unsaturated ester.

The Furan Fatty Acids (1: FFAs) are an important class of natural products and metabolites due to their observed nutritional health benefits and impact on inflammatory and cardiovascular diseases. ${ }^{1}$ To date, over 25 members have been discovered, and they are structurally characterized by a furan ring with a fatty acid side chain at the $\alpha_{1}$-position, a short alkyl side chain at the $\alpha_{2}$-position, a methyl group at the $\beta_{1}$-position, and a hydrogen or methyl group at the $\beta_{2}$-position (figure 1a). The FFAs are understood to originate from plant, algae and marine bacteria, and as a result they then accrue in higher order fish and mammals; therefore, the furan fatty acids are not produced de novo within humans and animals, but are accumulated through ingestion. ${ }^{\text {1a,2 }}$

(a) Furan fatty acids

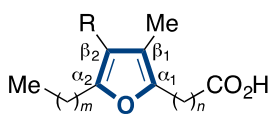

9D3 $\left(\mathrm{F}_{1}\right) m=2 ; n=8 ; \mathrm{R}=\mathrm{Me}$ $9 \mathrm{M} 5\left(\mathrm{~F}_{2}\right) m=4 ; n=8 ; \mathrm{R}=\mathrm{H}$ $9 \mathrm{D} 5\left(\mathrm{~F}_{3}\right) m=4 ; n=8 ; \mathrm{R}=\mathrm{Me}$ $11 \mathrm{D} 3\left(\mathrm{~F}_{4}\right) m=2 ; n=10 ; \mathrm{R}=\mathrm{Me}$ $11 \mathrm{M} 5\left(\mathrm{~F}_{5}\right) m=4 ; n=10 ; \mathrm{R}=\mathrm{H}$ $11 \mathrm{D} 5\left(\mathrm{~F}_{6}\right) m=4 ; n=10 ; \mathrm{R}=\mathrm{Me}$ $13 \mathrm{M} 5\left(\mathrm{~F}_{7}\right) m=4 ; n=12 ; \mathrm{R}=\mathrm{H}$ 1: General structure

13D5 $\left(\mathrm{F}_{8}\right) m=4 ; n=12 ; \mathrm{R}=\mathrm{Me}$

(b) Urofuran acids<smiles>Cc1oc(C(=O)O)c(C(=O)O)c1C</smiles>

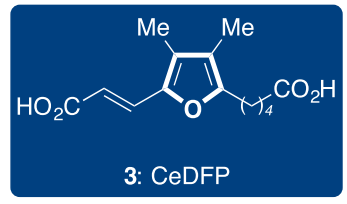

2a: $(n=2) \mathrm{CMPF}$ 2b: $(n=4)$ CMPentylF

Figure 1. (a) The general structure of the 8 predominant furan fatty acids; (b) three significant urofuran acid metabolites of the FFAs.
Once accumulated it is probable that the FFAs are further catabolized within animals via oxidation within the liver. This process gives rise to urofuran acids, whose structures can vary considerably depending on the species. Significantly, in humans, two principal urofuran acids 3-carboxy-4-methyl-5propyl-2-furanpropionic acid (CMPF, 2a) and 3-carboxy-4methyl-5-pentyl-2-furanpropionic acid (CMPentylF, 2b) (figure 1b) have been detected, with the levels of $\mathbf{2 a}$ being elevated in patients suffering from renal failure. ${ }^{1 \mathrm{c}, 3}$ However, the exact role and mode-of-action of CMPF (2a) in renal failure and particularly type- 2 diabetes has been intensely debated, and as yet to be fully elucidated. ${ }^{\text {la }}$

Another important catabolite is the tetra-substituted furan, 5[(1E)-2-carboxyethenyl]-3,4-dimethyl-2-furanpentanoic acid (CeDFP, 3). This urofuran acid has been detected in the urine of cattle ${ }^{4 a}$ and more significantly, can be found in appreciable amounts within the bile of sharks, making up almost $10 \%$ dry weight of the liver. ${ }^{4 b}$ Metabolite $\mathbf{3}$ differs significantly from CMPF (2a) and CMPentylF (2b) as the $\beta_{1}$ methyl group remains intact, and both the $\alpha_{1}$ and $\alpha_{2}$ side chains have undergone incomplete $\beta$-oxidation. To date this metabolite can only be obtained through isolation from shark livers, and consequently this method is unsustainable. Therefore, given this and the recent attention that the FFAs have garnered due to their potent antioxidant potential, we deemed that a first chemical synthesis of $\mathbf{3}$ was warranted. ${ }^{1,4 b, 5}$

Our approach to the total synthesis of $\mathbf{3}$ is outlined in the retrosynthetic analysis shown in scheme 1 . Judicious selection of the protecting group $\left(\mathrm{PG}^{1}\right)$ on the carboxyl group, and masking of the terminal acid of the $\mathbf{5}$ as the protected $\left(\mathrm{PG}^{2}\right)$ primary alcohol, will give tetra-substituted furan 4 . We envisaged using two key transformations to deliver this key 
tetra-substituted furan 4; (i) a Au-catalyzed intermolecular alkyne hydroarylation between a furan and a propiolate (5); and (ii) a metal-mediated cross coupling to introduce the methyl group of the furan. This approach reveals a trisubstituted furan $\mathbf{6}$ as a suitable precursor, that can be obtained via an electrophilic 5-endo-dig cyclization ${ }^{6}$ of propargyl 1,2diol 7.

Scheme 1. Retrosynthetic analysis of furan fatty acid metabolite 3 .<smiles>Cc1c(C(=O)O)oc(/C=C/C(=O)O)c1[N+](=O)[O-]</smiles><smiles>C=CCC</smiles>
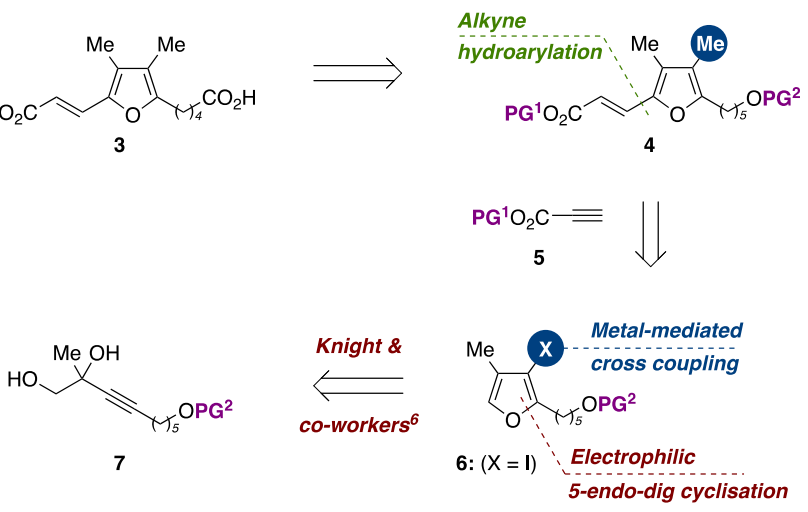

There are two plausible synthetic strategies to access tetrasubstituted furan 4; an intermolecular alkyne hydroarylation performed on $\mathbf{6}$, followed by a metal mediated cross coupling to give 4 (scheme $2 \mathrm{~b}$, Route A); alternatively the sequence of these two reactions can be reversed, where the key $\mathrm{Au}(\mathrm{I})$ hydroarylation transformation with $\mathbf{5}$ is performed with the trialkyl furan 9 (Route B). There are few examples of using an intermolecular hydroarylation transformation in target synthesis $;{ }^{7}$ however, an $\mathrm{Au}(\mathrm{I})$-catalyzed intermolecular alkyne hydroarylation using furan and 2-methylfuran has been reported. Reetz and co-workers demonstrated that furan (10a) and 2-methyfuran (10b) undergo regioselective hydroarylation with ethyl propiolate (11), giving the $Z$-products $(\mathbf{1 2 a}$ and 12b, respectively) in high yield. ${ }^{7 \mathrm{c}}$

Scheme 2. (a) Two plausible routes to tetra-substituted furan 4; (b) Au-catalyzed hydroarylation of ethyl propiolate with furan and 2-methylfuran.

(a)


Our approach began with the synthesis of the key trisubstituted furans $\mathbf{6}$ and $\mathbf{9}$, respectively (scheme 3 ). Reduction of methyl 6-heptynoate $\mathbf{1 3}$ with $\mathrm{NaBH}_{4}$ gave the alcohol in $82 \%$ isolated yield, which was subsequently protected as its TBDPS ether using standard conditions giving $\mathbf{1 4}$ in $89 \%$ yield. Deprotonation of $\mathbf{1 4}$ using ${ }^{n} \mathrm{BuLi}$ followed by addition of the THP protected ketone 16, and subsequent acid mediated deprotection of the THP-group, provided $\mathbf{1 7}$ in $77 \%$ yield over 2-steps. ${ }^{8}$ Propargyl-1,2-diol 17 could then be cyclized under modified conditions of Knight and co-workers ${ }^{6}$ to give the desired tri-substituted furan $\mathbf{6}$ in $45 \%$ isolated yield. The electrophilic 5-endo-dig cyclization of 6 using $\mathrm{I}_{2}$ proved problematic on this substrate and was complicated by the further electrophilic iodination of the product; however, this over iodination could be suppressed by performing the reaction in acetonitrile and ensuring careful control of the reaction temperature. ${ }^{9}$ Conversion of the iodine at the $\mathrm{C}_{3}$ position to the required methyl group in $\mathbf{9}$ could be achieved using three methods. Palladium cross-coupling with trimethylboroxine under Suzuki-conditions ${ }^{10}$ gave trialkylfuran 9 in a modest $52 \%$ yield. Alternatively, the action of ${ }^{n} \mathrm{BuLi}$ on $\mathbf{6}$ at low temperature, followed by subsequent treatment of the lithiate with $\mathrm{MeI}^{8 \mathrm{a}}$ gave $\mathbf{9}$ in a more acceptable $67 \%$ yield. Finally, we found direct iodine-methyl exchange using a MeLi.LiBr complex in THF to be far superior, delivering 9 in $85 \%$ yield.

Scheme 3. Preparation of tri-substituted iodofuran 6 and trialkyl furan 9.
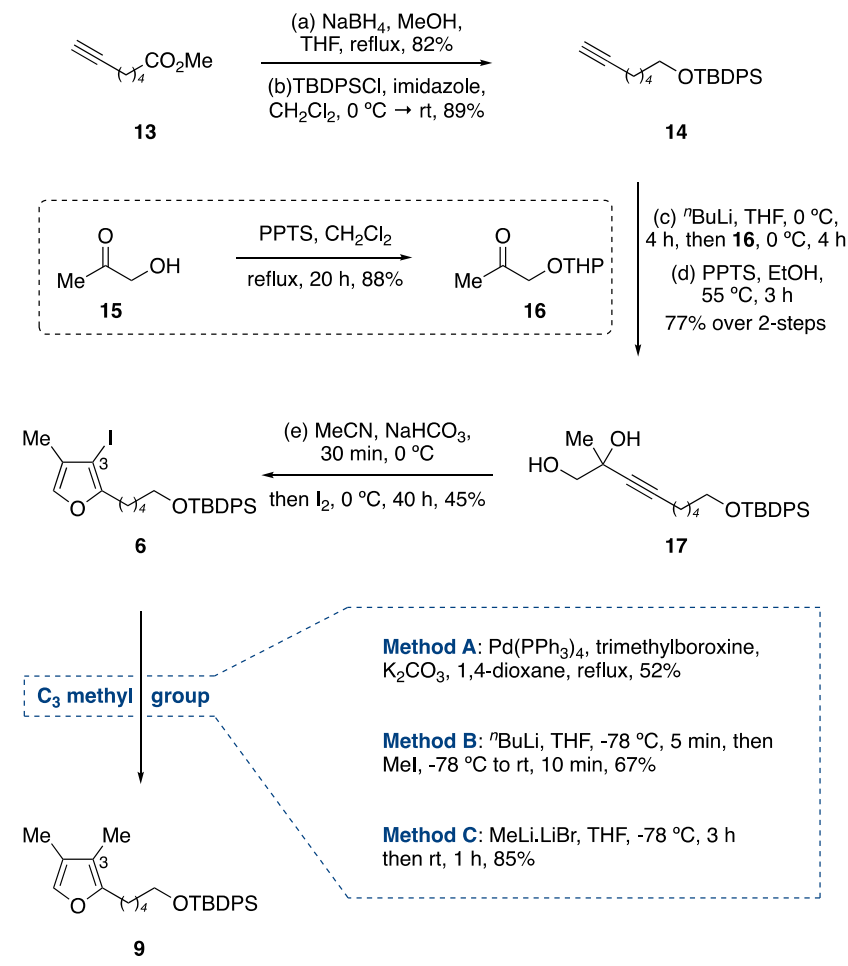

With iodofuran 6 in-hand we elected to examine Route A (scheme 4 and table 1). Accordingly, using adapted conditions of $\mathrm{Reetz}^{6 \mathrm{c}}$ and a $\mathrm{PPh}_{3} \mathrm{AuCl} / \mathrm{AgOTf}$ catalysts system we were able to hydroarylate $\mathbf{6}$ using an excess of ethyl propiolate (11) in an encouraging $13 \%$ isolated yield (entry 1). As expected, the product isolated was predominantly of Z-configuration, with the ${ }^{1} \mathrm{H}$ NMR signals for the double bond appearing as doublets at $\delta 6.51(J=12.4 \mathrm{~Hz})$ and $\delta 5.71(J=12.8 \mathrm{~Hz}) \mathrm{ppm}$, respectively. The Johnphos-Au(I) complex 19 has been shown 
to be a superior $\mathrm{Au}(\mathrm{I})$-complex in a diverse range of inter- and intramolecular processes, ${ }^{11}$ and therefore this was selected as our preferred $\mathrm{Au}(\mathrm{I})$ complex for optimization over the $\mathrm{PPh}_{3} \mathrm{AuCl} / \mathrm{AgOTf}$ system.

Scheme 4 and Table 1. Au-catalyzed hydroarylation of iodofuran 6 to give $18 .^{a}$

\begin{tabular}{|c|c|c|c|c|c|c|}
\hline${ }^{\mathrm{Me}}$ & 6 & $\begin{array}{c}\stackrel{\mathrm{Au}(\mathrm{l}) \text { catalyst }}{\longrightarrow} \\
\mathrm{MeNO}_{2} \\
\mathrm{EtO}_{2} \mathrm{C} \rightleftharpoons \\
\mathbf{1 1}\end{array}$ & ${ }_{2} \mathrm{C}$ & 18 & & $\begin{array}{l}\text { 19: JohnPhos } \\
\text { Au complex }\end{array}$ \\
\hline entry & $\begin{array}{c}\text { cat. } \\
(\mathrm{mol} \%)\end{array}$ & $\begin{array}{c}11 \\
\text { [equiv] }\end{array}$ & $\begin{array}{c}\text { time } \\
{[\mathrm{h}]}\end{array}$ & $\begin{array}{c}\text { conc. } \\
{[\mathrm{M}]}\end{array}$ & $\mathrm{Z} / \mathrm{E}^{b}$ & $\begin{array}{c}18 \\
{[\%]^{c}}\end{array}$ \\
\hline 1 & $5^{d}$ & 10 & 24 & 3 & $95 / 5$ & 13 \\
\hline 2 & 5 & 10 & 24 & 3 & $48 / 52$ & 33 \\
\hline 3 & 5 & 10 & 24 & 6 & $67 / 33$ & 23 \\
\hline 4 & 3 & 10 & 24 & 3 & $45 / 55$ & 37 \\
\hline 5 & 3 & 5 & 36 & 1 & $34 / 66$ & 42 \\
\hline 6 & 3 & 5 & 48 & 1 & $25 / 75$ & 58 \\
\hline
\end{tabular}

${ }^{a}$ Reactions performed in $\mathrm{MeNO}_{2}$ at room temperature with $\mathrm{Au}(\mathrm{I})$ complex 19, unless otherwise stated. ${ }^{b}$ Determined by ${ }^{1} \mathrm{H}$ NMR. ${ }^{c}$ Isolated yields. ${ }^{d} \mathrm{PPh}_{3} \mathrm{AuCl} / \mathrm{AgOTf}$ catalyst system.

Replacing the $\mathrm{PPh}_{3} \mathrm{AuCl} / \mathrm{AgOTf}$ catalyst system with $\mathrm{Au}(\mathrm{I})$ complex 19 had an immediate effect, giving the desired product $\mathbf{1 8}$ in $33 \%$ isolated yield (entry 2); whereas a doubling of concentration of the reaction mixture had a detrimental effect on yield (entry 3 ). A reduction of catalyst loading to 3 mol \% was tolerated without any reduction in yield (entry 4). To improve purification, it was desirable to reduce the amount of ethyl propiolate (11), and accordingly, we observed that by decreasing the concentration, and increasing the reaction time, the equivalents of ethyl propiolate could be reduced significantly while maintaining overall chemical yield (entry 5). Finally, by extending the reaction time further to $48 \mathrm{~h}$ we achieved an acceptable yield of $58 \%$ for $\mathbf{1 8}$ (entry 6 ).

From table 1 it can be observed that the Johnphos $\mathrm{Au}(\mathrm{I})$ complex 19, gives significant $Z / E$ mixtures in the product 18, as compared to $\mathrm{PPh}_{3} \mathrm{Au}(\mathrm{I}) \mathrm{OTf}$. It transpires that extended reaction times lead to increased amounts of the $E$ stereoisomer, as highlighted in entries 5 and 6 , respectively. However, the $Z / E$ ratio from the $\mathrm{Au}(\mathrm{I})$-catalyzed hydroarylation was inconsequential, as we were able to cleanly isomerize the $Z / E$ mixtures obtained from the hydroarylation of 6 to its $E$-isomer upon treatment with $\mathrm{I}_{2}$ (scheme 5a). ${ }^{12}$ This was confirmed by the double bond signals of $(E)-\mathbf{1 8}$ now appearing in the ${ }^{1} \mathrm{H}$ NMR at $\delta 7.44(J=15.6$ $\mathrm{Hz})$ and $\delta 6.21(J=15.6 \mathrm{~Hz}) \mathrm{ppm}$, respectively.

Having established conditions for the hydroarylation and synthesis of 18, we then applied these reaction conditions to the trialkyfuran 9 (scheme 5b). Pleasingly, we observed full conversion to the desired tetra-substituted furan $\mathbf{2 0}$ after a reaction time of $64 \mathrm{~h}$; and upon exposure to $\mathrm{I}_{2}$, we subsequently converted this to $(E)-\mathbf{2 0}$ in $85 \%$ yield over these 2-steps. Alternatively, $(E)$-20 could be synthesized upon exposure of iodo-furan $(E)-\mathbf{1 8}$ to palladium cross-coupling conditions with trimethylboroxine, albeit in a very poor yield of $9 \%$. Attempts at introducing the $\mathrm{C}_{3}$-methyl group using the transmetalation protocols outlined in scheme 3 were unsuccessful due to the presence of the sensitive unsaturated ester at $\mathrm{C}_{5}$. This result confirms that Route B (scheme 2) is the most efficient method to access $(E)-20$. Firstly, the cross-coupling of the $\mathrm{C}_{3}$-iodo is superior when performed on the furan $\mathbf{6}$, and secondly, the resultant trialkyfuran $\mathbf{9}$ is better suited to the subsequent $\mathrm{Au}(\mathrm{I})$-catalyzed alkynyl hydroarylation transformation, likely due to its increased nucleophilicity compared to furan $\mathbf{6}$.

Scheme 5. (a) I2 mediated isomerization giving (E)-18; (b) Synthesis of tetra-substituted furan $(E)-20$.
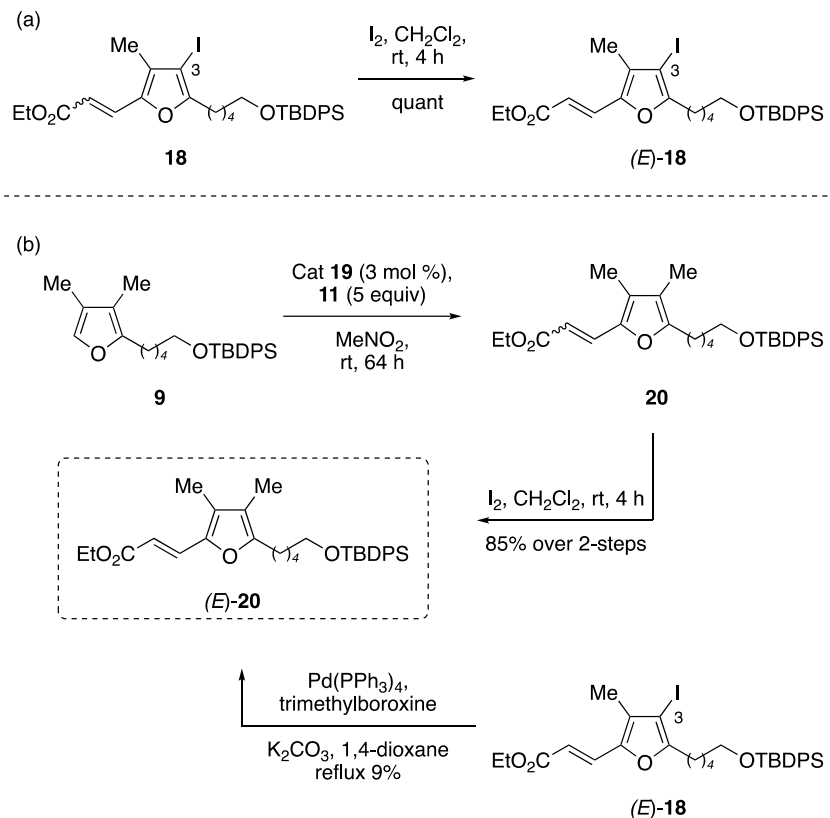

The completion of the synthesis of $\mathbf{3}$ is shown in scheme 6 . Silyl deprotection of (E)-20 was achieved using TBAF in a quantitative yield, giving primary alcohol 21. Oxidation to the 2-furanpentanoic acid proved capricious, with standard PDC conditions under several solvent conditions proving unproductive; however, the use of TPAP, with an NMO cooxidant, finally gave the desired acid $\mathbf{2 2}$ in $50 \%$ isolated yield. The ethyl ester of $\mathbf{2 2}$ was then saponified using $\mathrm{LiOH}$ giving the 3 in $45 \%$ isolated yield.

Scheme 6. Completion of the synthesis of CeDFP (3).

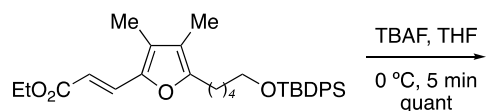

$(E)-20$
21
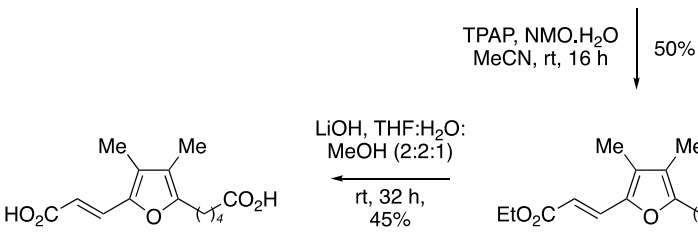

3: $\mathrm{CeDPF}$
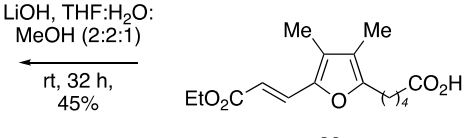

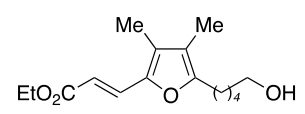

In summary, a first total synthesis of the furan fatty acid metabolite 5-[(1E)-2-carboxyethenyl]-3,4-dimethyl-2-furan pentanoic acid (CeDFP, 3) has been accomplished in 10-steps (4.1\% overall yield) from commercially available methyl 6heptynoate (12). The spectroscopic data for the synthesized material was in agreement with that reported ${ }^{4 \mathrm{~b}}$ for the isolated natural product. Features of this synthesis include (a) an iodine promoted 5-endo-dig cyclization of an 1,2-akyne diol under the adapted condition of Knight; $^{6}$ (b) a methyl-lithium 
mediated insertion of the $\mathrm{C}_{3}$-methyl group; and notably (c) an $\mathrm{Au}(\mathrm{I})$-catalyzed intermolecular hydroarylation to introduce the unsaturated ester. Importantly, in the approach described, the sequence in which steps (b) and (c) were implemented was found to be crucial. Given the importance of the furan fatty acids, and their oxidation metabolites (the urofuran acids), this first total synthesis can provide an effective model for synthesizing analogues of CeDFP. Furthermore, this approach highlights the use of $\mathrm{Au}(\mathrm{I})$ intermolecular hydroarylation as a suitable tactic in synthesizing these valuable natural products and metabolites.

\section{ASSOCIATED CONTENT}

\section{Supporting Information}

The Supporting Information is available free of charge on the ACS Publications website.

General experimental procedures, characterization data, and ${ }^{1} \mathrm{H}$ and ${ }^{13} \mathrm{C}$ NMR spectra of new compounds. (PDF)

\section{AUTHOR INFORMATION}

\section{Corresponding Author}

* E-mail: M.C.Kimber@lboro.ac.uk

* E-mail: $\underline{\text { G.J.Pritchard@ @boro.ac.uk }}$

\section{ORCID}

Marc C. Kimber: 0000-0003-2943-1974

Gareth J. Pritchard: 0000-0002-2925-1722

\section{Notes}

The authors declare no competing financial interest.

\section{ACKNOWLEDGMENT}

We gratefully acknowledge financial support from Loughborough University. We also thank Dr. Mark Edgar (Loughborough University) for assistance with NMR assignments.

\section{REFERENCES}

(1) (a) Xu, L.; Sinclair, A. J.; Faiza, M.; Li, D.; Han, X.; Yin, H.; Wang, Y. Prog. Lip. Res. 2017, 68, 119; (b) Spiteller, G. Mol. Biotechnol. 2007, 37, 5; (c) Spiteller, G. Lipids 2005, 40, 755 .

(2) (a) Hannemann, K.; Puchta, V.; Simon, E.; Ziegler, H.; Ziegler, G.; Spiteller, G. Lipids 1989, 24, 296; (b) Batna, A.; Scheinkönig, J.; Spiteller, G. Biochem. Biophys. Acta 1993, 1166, 171; (c) Shirasaka, N.; Nishi, K.; Shimizu, S. Biochem. Biophys. Acta 1997, 1346, 253.

(3) Liebich, H. M.; Pickert, A.; Tetschner, B. J. Chromatogr. 1984, 289, 259.

(4) (a) Bauer, S.; Spiteller, G. Helv. Chim. Acta 1985, 68, 1635; (b) Wakimoto, T.; Kondo, H.; Nii, H.; Kimura, K.; Egami, Y.; Oka, Y.; Yoshida, M.; Kida, E.; Ye, Y.; Akahoshi, S.; Asakawa, T.; Matsumura, K.; Ishida, H.; Nukaya, H.; Tsuji, K.; Kan, T.; Abe, I. Proc. Nat. Acad. Sci. 2011, 108, 17533.

(5) For recent examples see (a) Lemke, R. A. S.; Peterson, A. C.; Ziegelhoffer, E. C.; Westphall, M. S.; Tjellström, H.; Coon, J. J.; Donohue, T. J. Proc. Nat. Acad. Sci. 2014, 111, E3450; (b) Müller, M.; Hogg, M. Ulms, K.; Vetter, W. J. Agric. Food Chem. 2017, 65, 7919; (c) Lee, R. J.; Lindley, M. R.; Pritchard, G. J.; Kimber, M. C. Chem. Commun. 2017, 53, 6327.

(6) (a) Knight, D. W.; Smith, A. W. T. Tetrahedron 2015, 71, 7436; (b) Knight, D. W.; Smith, A. W. T. Heterocycles
2012, 84, 361; (c) Evans, A. B.; Flügge, S.; Jones, S.; Knight, D. W.; Tan, W. -F. Arkivoc 2008, part x, 95; (d) Bew, S. P.; El-Taeb, G. M. M.; Jones, S.; Knight, D. W.; Tan, W. -F. Eur. J. Org. Chem. 2007, 5759.

(7) For reviews see (a) Muratore, M. E.; Echavarren, A. M. Gold-catalyzed hydroarylation of alkynes. In The Chemistry of Organogold Compounds; Rappoport, Z.; Leibman, J. F.; Marek, I., Ed.; John Wiley \& Son: Chichester, UK; 2014, p 805; (b) Kitamura, T. Eur. J. Org. Chem. 2009, 1111; (c) for the hydroarylation of propiolates with furan see Reetz, M. T.; Sommer, K. Eur. J. Org. Chem. 2003, 3485.

(8) A TBS protecting group was initially trialed in this synthetic sequence but ultimately proved unstable during the THP deprotection, hence the judicious selection of the TBDPS protecting group.

(9) Please see the supporting information for details of the reaction conditions screened.

(10) (a) Moody, C. J.; Kimber, M. C. Chem. Commun. 2008, 591; (b) Gray, M.; Andrews, I. P.; Hook, D. F.; Kitteringham, J.; Voyle, M. Tetrahedron Lett. 2000, 41, 6237.

(11) (a) Nieto-Oberhuber, C.; López, S.; Muñoz, M. P.; Cárdenas, D. J.; Buñuel, E.; Nevado, C.; Echavarren, A. M. Angew. Chem. Int. Ed. 2005, 44, 6146; (b) Ferrer, C.; Echavarren, A. M. Angew. Chem. Int. Ed. 2006, 45, 1105; (c) Menon, R. S.; Findlay, A. D.; Bissember, A. C.; Banwell, M. G. J. Org. Chem. 2009, 74, 8901

(12) A palladium catalyzed Heck coupling of ethyl acrylate with 6 failed to deliver $E-18$; see Tsuji, J.; Nagashima, H. Tetrahedron 1984, 40, 2699. 


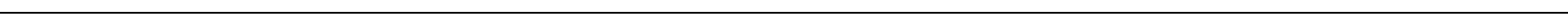

